\title{
Graduate programs in physics education research: A USA based survey
}

\author{
Ramón S. Barthelemy \\ Department of Physics and Astronomy, The University of Utah, Salt Lake City, UT 84112 \\ Mirna Mohamed ${ }^{1}$, Alexis V. Knaub ${ }^{2}$, Charles Henderson ${ }^{3}$ \\ ${ }^{1}$ Department of Physics and Astronomy, The University of Utah, Salt Lake City, UT 84112 \\ ${ }^{2}$ American Association of Physics Teachers, College Park, MD 20740 \\ ${ }^{3}$ Department of Physics and Malinson Institute for Science Education, Western Michigan \\ University, Kalamazoo, MI 49008
}

This article outlines survey results seeking to understand USA Physics Education Research (PER) Ph.D. programs. The survey explored research group composition, the number of graduates, courses taken and more. The survey was sent to a list of PER research group leaders created by crowdsourcing from the PER community. Of the 46 PER Ph.D. programs identified and invited to the survey, 25 usable responses were received. The majority of programs were in departments of physics with fewer in schools of education or institutes of science education. Most programs required graduate physics course work, with fewer requiring research methodology courses. Only five required a course in PER. The majority of graduates into academic careers. However, a robust minority pursued careers in the private sector. The survey results allow us to estimate the size of the PER community in research groups at $\mathrm{PhD}$ granting institutions to be $\mathrm{n}=487$ people with $\mathrm{n}=156$ P.h.D. students.

2020 PERC Proceedings edited by Wolf, Bennett, and Frank; Peer-reviewed, doi.org/10.1119/perc.2020.pr.Barthelemy Published by the American Association of Physics Teachers under a Creative Commons Attribution 4.0 license. Further distribution must maintain the cover page and attribution to the article's authors. 


\section{INTRODUCTION}

Physics Education Research (PER) is a unique and diverse subfield of physics with programs located in schools of education, departments of physics, and science education institutes. Though fairly new, with annual conferences that began in 1997, PER is now represented in many physics programs across the US [1]. Some work has been done exploring the experiences of graduate student and post-doc hiring in PER [2-5], showing that many students switch into the field from other subfields and largely aspire to academic careers. However, no work has specifically looked at the content of PER Ph.D. programs and the final careers of graduate students in PER.

It is important for the PER community to understand the experiences and training of future scholars in order to fully realize the strengths and limitations of our field. These results may also suggest policy changes to improve or diversify the current training of Ph.D. students in PER. This article offers a look into the programs and careers of graduates with Ph.D.s in PER through a survey of US-based PER Ph.D. programs.

\section{METHODOLOGY}

To conduct a survey on US Ph.D. programs in PER the researchers first built a comprehensive list of US Ph.D. PER programs. The focus was on the USA in order to control for the varying differences that exist generally between Ph.D. programs in the USA and globally. The list creation was done by creating an online document filled in with programs identified on the PER ComPADRE website [6]. This list was then emailed out to multiple PER list-servs and individuals asking for feedback and updates. This was done to identify additional programs, collect contact information for each program, and eliminate programs no longer in existence. When this list was finalized, it was analyzed for each program by doing an internet search to verify the existence of the program, and that it offered a Ph.D. in PER. The final list was comprised of 46 institutions with contact information of their research group leaders.

Research group leaders from each institution on the list were sent an invitation to participate in a survey on their graduate program. Potential participants were sent multiple invitations, up to three, to complete the survey. The survey was designed to collect basic information about doctoral PER programs. This included: program's department, classes required, positions after doctoral completion, funding sources for groups, and more. With a response rate of $54 \%, 25$ usable responses were collected.

\section{RESULTS}

The results presented below represent the responses of 25 PER programs of the 46 surveyed in the United States.

\section{A. Academic locations}

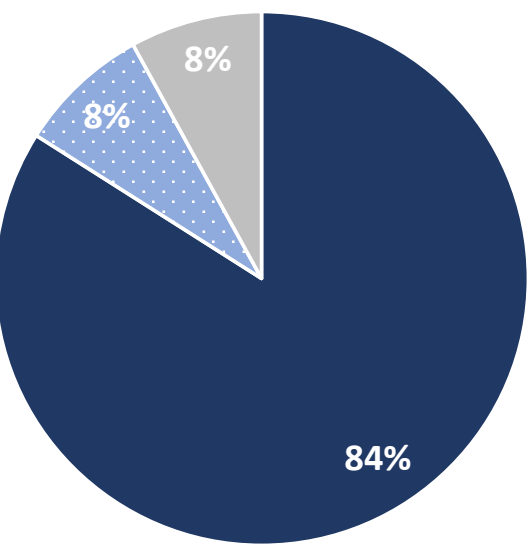

n Department of Physics $\approx$ Other School of Education

FIG. 1. Academic locations of PER Ph.D. programs.

Figure 1 shows the institutional location of PER Ph.D. programs surveyed. The majority of programs identified themselves as being in departments of physics $(n=21,84 \%)$, with fewer programs identifying themselves as being in schools of education $(\mathrm{n}=2,8 \%)$, and other departments $(\mathrm{n}=2$, $8 \%$ ). The two "other" departments were interdisciplinary programs in science education.

\section{B. PER research group composition}

Fig. 2 shows which kinds of position types were represented in each research group. Faculty were the most represented $(\mathrm{n}=25,100 \%)$, followed by graduate students $(\mathrm{n}=23,92 \%)$ and non-tenure line faculty members $(\mathrm{n}=16$, $64 \%$ ). There were also strong representations of undergraduate students $(\mathrm{n}=14,56 \%)$ and post-doctoral scholars $(12,48 \%)$. Research associates $(n=5,20 \%)$ and other positions (such as a visiting professor or support staff) $(n=4,16 \%)$ were the least represented.

Fig. 3 represents all reported PER members in all responding PER research groups $(\mathrm{n}=265)$, graduate students were the largest group with $32 \%(\mathrm{n}=85)$ of persons, followed by tenure line faculty members $(n=49,18 \%)$ and undergraduate students $(\mathrm{n}=46,17 \%)$. Research associates $(n=21,8 \%)$ and other positions $(n=13,5 \%)$ showed the least representation. Factoring in the response rate $(n=25 / 46)$ it is possible to estimate the total PER community in research groups granting doctoral degrees in PER to be 487 persons with 156 P.hD. students. It should be noted that this number may be an overestimate if primarily large PER $\mathrm{PhD}$ programs replied to the survey. 


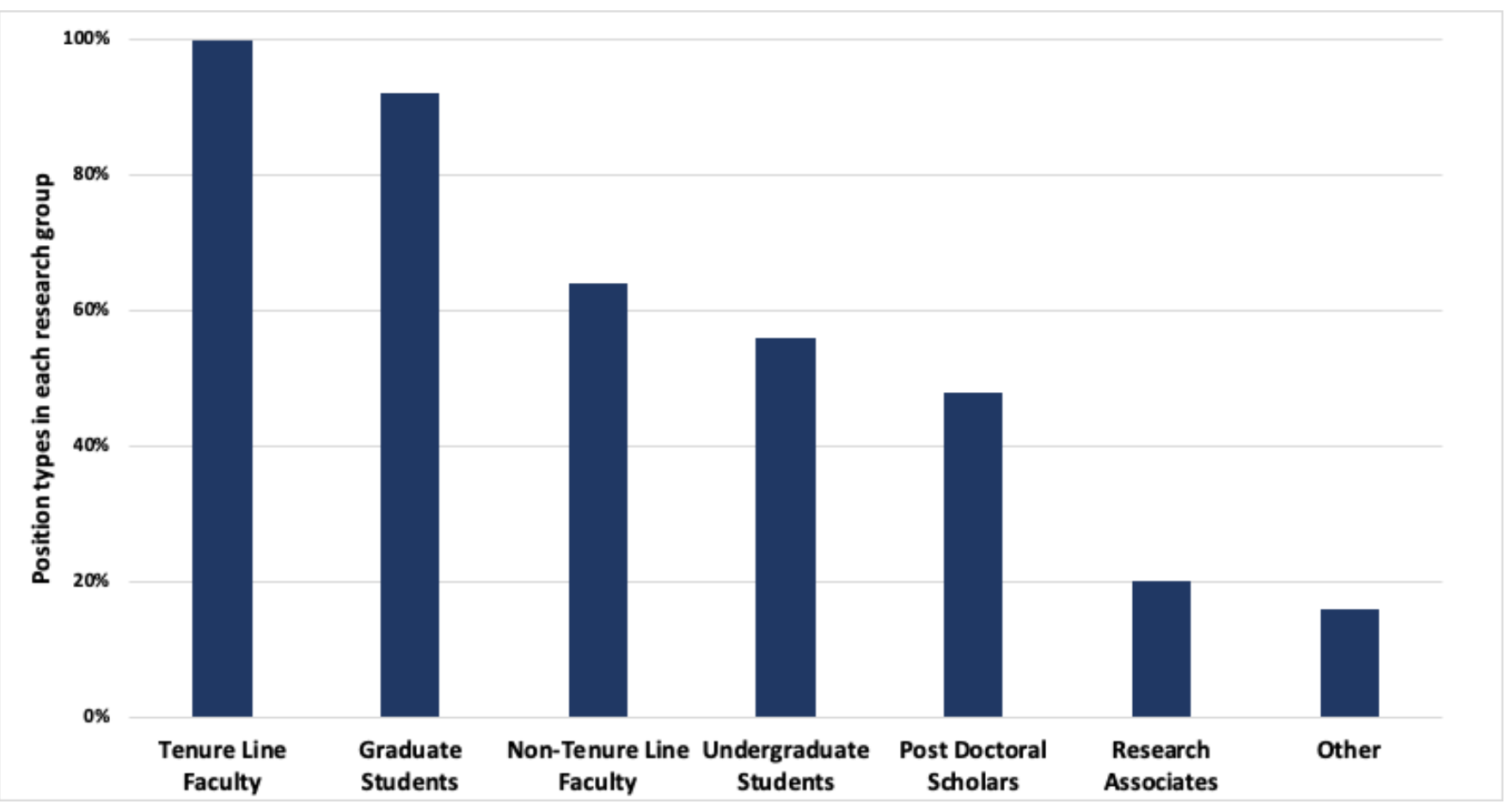

FIG. 2. Position types reported by each respondent represented in their research groups

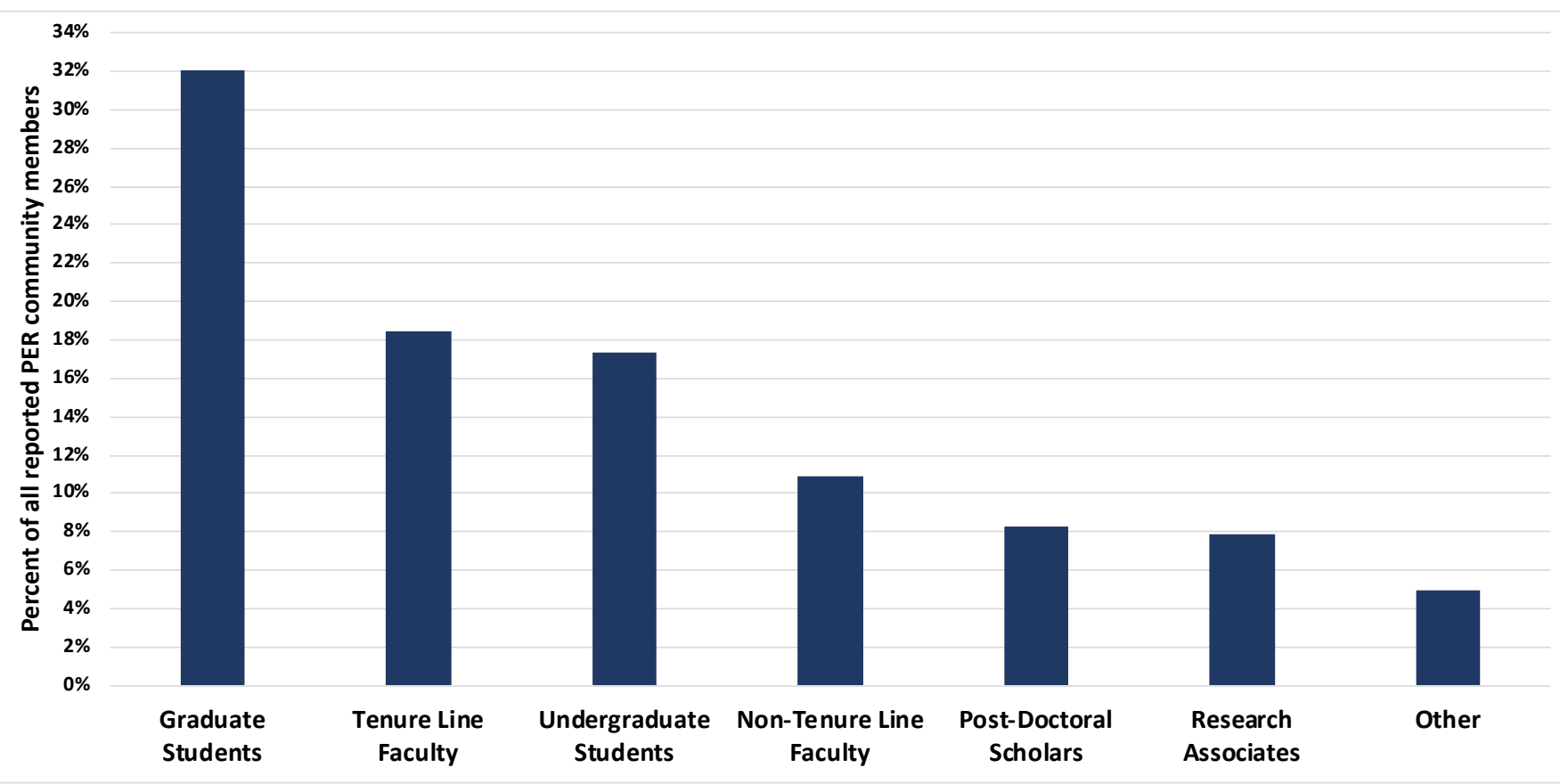

FIG. 3. PER members represented in all PER research groups

\section{Ph.D. Program Requirements}

Participants in the survey were asked about the time required to complete their doctoral PER programs. The answers were confined to 3 categories. The majority of PER programs took 5 to 6 years $(n=16,64 \%)$ to complete, followed by 0 to 4 years $(n=5,20 \%)$ and others requiring 6 or 7 years $(n=3,12 \%)$. Some of the programs with shorter completion times may have required a master's degree for admittance.

As shown in Fig. 4 below, passing graduate physics courses $(n=23,92 \%)$ and qualifying examination in physics content $(n=19,76 \%)$ are common program requirements, 
followed by graduate-level education and qualitative and quantiative research methodology courses. There are fewer programs that require a specific physics education research course $(n=5,20 \%)$ and peer-reviewed publications $(n=4$, $16 \%$ ) in Ph.D. programs. It should be mentioned that all universities participating in the survey stipulated at least 2 of the requirements mentioned. The programs not requiring graduate courses in physics were not in departments of physics and or astronomy and may have admitted students with previous training in graduate physics.

\section{Career paths}

The results indicated that the many of programs have had more than $7(n=10,40 \%)$ graduates or between 1 and 6 graduates $(n=10,40 \%)$. A minority of programs had no graduates $(n=5,20 \%)$. The survey asked respondents to identify the positions taken by their graduates right after completing their Ph.D. as well as their final positions.

Figure 5 shows a comparison between the initial $(n=62)$ and $(n=40)$ final positions of graduates with Ph.D.s in PER. It illustrates that the majority of PER doctoral recipients initially were in non-tenure line faculty $(n=17,27 \%)$ or postdoctoral positions for their careers $(n=14,23 \%)$. For their final positions many graduates with Ph.D.s in PER were reported to end up in tenure line positions $(n=10,25 \%)$ and private sector $(n=9,22 \%)$.

\section{LIMITATIONS}

The limitations of this study primarily derive from the creation of the graduate program list and the response rate. The list was created using community list-servs which may have over represented departments of physics and underrepresented schools of education. It is also possible that PER is occurring in communities not traditionally represented in physics spaces, i.e., K-12 education. Secondly, the survey only received 25 responses of 46 potential participants. Consequently, the results are delimited to these respondents and not necessarily all PER Ph.D. programs.

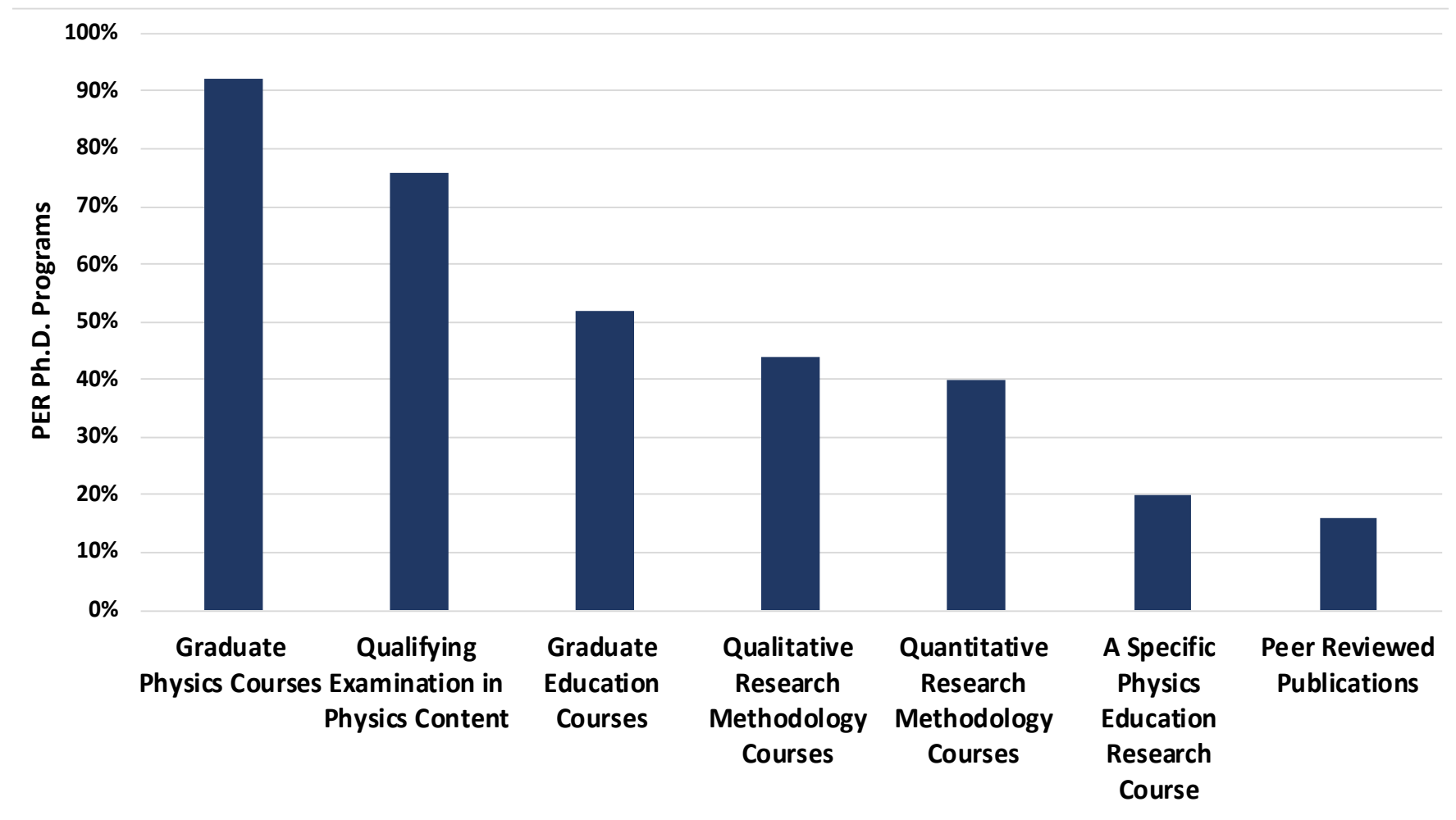

FIG. 4. Requirements for completing a Ph.D. in PER. 


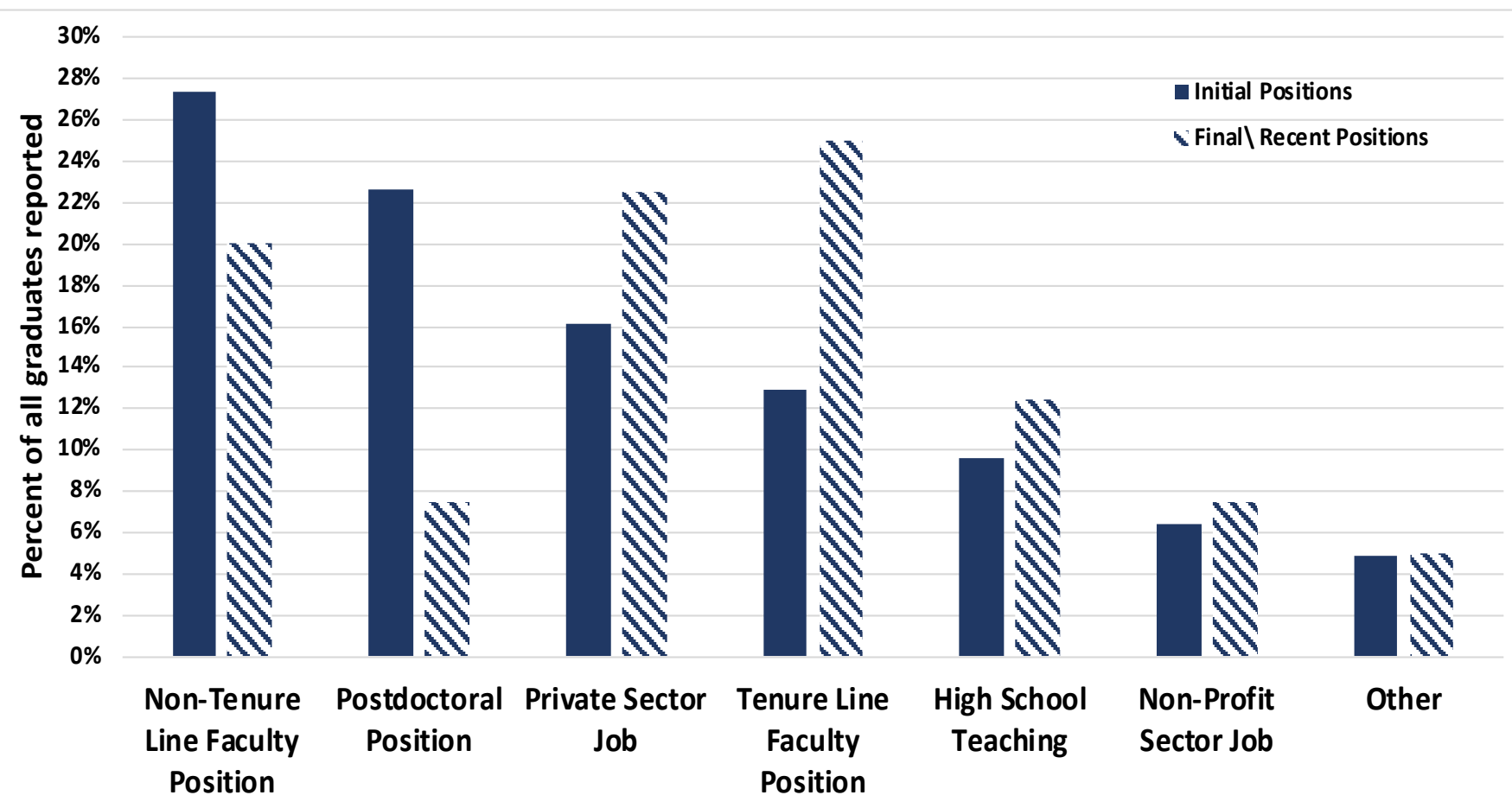

FIG. 5. Comparison between Ph.D. holders initial and final positions

\section{CONCLUSIONS}

The results of the participating programs demonstrate that the majority of PER Ph.D. programs reside in departments of physics. Most graduate programs prepare students through graduate physics course work, with only five requiring PER specific classes and about half requiring qualitative or quantitative research methodology coursework. The career pathways of students were fairly broad, with the majority going into academic positions with a strong minority pursuing non-academic positions. Factoring in the response rate, there are 156 estimated $\mathrm{PhD}$ students in PER in the US out of the 487 research group members at doctoral granting institutions.

This strong showing of students pursuing non-tenure line or academic careers suggest the importance of professional development opportunities for students to learn more about their options as well as develop skills necessary for private sector employment. Furthermore, only a small handful of programs taught a course in PER with only about half requiring research methodology courses. It is likely that many PER programs could be strengthened by more targeted preparation in PER and science education research methods. It may also point to a potential gap in the skill set of current and future scholars in the field.

Future research on graduate programs in PER should consider how our community's training impacts the kinds of research being conducted, and how this may influence the larger culture of physics education nationwide.
Understanding the training and preparation of graduate students in PER may be informative and important to sustaining future leadership and the field as a whole. It would also be valuable to understand the research role groups at non-PhD granting institutions play in the PER community, and this warrants study as well.

\section{ACKNOWLEDGEMENTS}

The authors would like to thank the PER community and all survey respondents for helping to build the program list and complete the associated survey.

[1]R. J. Beichner, An introduction to physics education research, in Getting started in physics education research, edited by $\mathrm{C}$. Henderson, and K. A. Harper (American Association of Physics Teachers, College Park, MD, 2009).

[2]B. Van Dusen, R. Barthelemy, and C. Henderson, "Educational trajectories of graduate students in per," Physical Review Special Topics- Physics Education Research 10, (2014).

[3]R. S. Barthelemy, B. Van Dusen, and C. Henderson, "Physics education research: A research subfield of physics with gender parity," Physical Review Physics Education Research, (2015).

[4]R. S. Barthelemy, C. Henderson, and M. L. Grunert, "How did they get here?: Pathways in physics education research," Physical Review Special Topics- Physics Education Research, (2013).

[5]A. V. Knaub et al., "Experiences of postdocs and principal investigators in physics education research postdoc hiring," Physical Review Physics Education Research 14, (2018). [6]https://www.compadre.org/per/, "Per central," 2020). [7]https://sites.google.com/site/pergraduatestudents/what-ispercogs, "What is percogs," 2020). 